\title{
Access to Justice for Older People in Australia
}

\author{
Susannah Sage-Jacobson*
}

\begin{abstract}
The past decade in Australia has seen renewed policy interest in access to justice. In turn this has highlighted the need for evidence-based research on the legal needs of socially and economically disadvantaged groups. Older persons, or people over the age of 65, have been recognised as a distinctly burdened group who are vulnerable to substantial and distinctive legal problems with adverse impacts on their life circumstances. Yet the legal needs of this group remain largely unmet, hidden from the legal service providers and complaint handling bodies. This article provides an overview of recent research on legal needs in Australia and internationally. It explains that there needs to be further targeted empirical research to identify the substantive reasons why older people do not currently enjoy equality before the law.
\end{abstract}

\section{INTRODUCTION}

Equality before the law and access to justice have long been a priority in Australian justice policy. Particular recent concerns include perceived rising costs of legal services and operating legal institutions, and inefficiencies in the civil law system. Empirical legal needs research has provided key evidence about which groups of people within the Australian population experience unmet legal needs and where barriers in access to the legal system occur. This research in Australia and internationally has confirmed that while older people's legal needs may not be as prevalent as compared with other disadvantaged groups, they are the least likely to access assistance, or gain resolution or satisfaction from the law. Unfortunately research has, so far, stopped short of fully identifying the reasons for the specific impediments that limit older people's access to legal services and why they tolerate the least optimal outcomes from the law.

Current ageing policy in Australia recognises access to justice is consistent with ensuring standards of protection and services in both gerontology and law. Access to justice policy however has not recognised or prioritised the distinctive legal needs of older people, nor has it generated the empirical research required to identify what the real barriers to access to justice for older people are. Instead, current justice policy reflects a narrow efficiency focused view of the limitations on legal services which focuses on the personal attitudes and attributes of those groups

* The author would like to thank Professor Kathy Mack for her valuable comments on the early drafts of this article. Thanks also to Caroline Sage and the anonymous reviewers for their useful suggestions. 
who do not access services, and are therefore believed to have successfully resolved their legal disputes on their own. In the case of older adults, a more specific assumption/belief appears to be that the psychological resilience of older people may explain their lack of access to legal services, but this also remains untested and unproven. Without evidence-based understanding, the real causes of failure in the formal legal system to meet the legal needs of ageing Australians are not identified and necessary reform will not be achieved. The priorities for future research and policy development in the next wave of access to justice must avoid these assumptions and tackle the difficult question of what older people want the public legal system to provide.

\section{Australian Legal Needs Research and Older PeOPle}

\section{A Access to Justice Research}

Access to justice research has been described internationally as having historically occurred in four distinct or classic thematic waves. ${ }^{1}$ In Australia, the previous four waves of policy reform have been summarised as focusing on: equality of access to legal services; structural inequalities within the justice system; informal justice and preventing disputes from occurring and escalating; and efficiency and competition to drive down costs. $^{2}$ All of these waves of law reform involved analysis of the existing justice system to develop strategies to allow equality of entry by all users of the legal system. ${ }^{3}$ Based on 'universalist'4 ideals, inquiry was focused on levelling the playing field by recognising the impact of social disadvantage on access to existing justice system institutions and removing the barriers to these services.

Over the past two decades in Australia a new 'fifth wave' of law reform in the area of access to justice in Australia has developed with a broader theoretical underpinning which has seen a shift in perspective

1 See Mauro Cappelletti and Bryant Garth, 'Access to Justice: The Newest Wave in the Worldwide Movement to Make Rights Effective' (1978) 27(2) Buffalo Law Review 181. This concept is also discussed in Rodney MacDonald, 'Access to Justice and Law Reform' (1990) 10 Windsor Yearbook of Access Justice 287.

2 Access to Justice Taskforce, Attorney-General's Department, A Strategic Framework for Access to Justice in the Federal Civil Justice System (2009) 3.

3 The first empirical study in Australia was part of the Commonwealth Government's Access to Justice Action Plan, conducted between 1996 and 1999 of the expressed legal needs of Australian citizens in order to inform the allocation of Commonwealth legal aid funding; The Australian Law Reform Commission's major study of the federal civil justice system, Managing Justice, Report 89 (2000), also focused on access to justice issues but focused on users or consumers of existing legal services rather than the wider notion of unmet legal needs.

4 Term discussed in Richard Moorhead and Pascoe Pleasence, 'Access to Justice after Universalism: Introduction' (2003) 30(1) Journal of Law and Society 1, cited in Richard Moorhead and Pascoe Pleasence (eds), After Universalism: Re-engineering Access to Justice (Blackwell Publishing, 2003). 
towards analysing the community's legal needs. ${ }^{5}$ The fifth wave of reform integrated the approaches of the previous four waves of reform and drew on self-regulation and democratic theory to promote normative notions of substantive justice within the community. ${ }^{6}$ In essence, this approach gave a coherent framework for conceptualising legal needs, which invited empirical research to test the key assumptions about what the community actually wants from the justice system and what they need in order to claim and protect their rights. It provided a base from which to address both of the unanswered underlying questions of whose access to which justice.

While legal needs research provide some of the evidence required to drive much needed policy reform, empirical researchers have remained careful to frame their results as reflecting the inherent complexity of legal needs rather than signalling clear policy priorities. While analysing the legal needs research from the perspective of older people may appear to address the whose access question, the demographic variables in the composition and features of the many diverse cohorts of older people continually change over time. Further, the question of which justice involves a more complex analysis than considering only what the community itself believes that it wants.

\section{B Influence of International Legal Needs Research}

During the 1990s, international empirical research activity on legal needs increased significantly. The most comprehensive projects and surveys of the legal needs of the public were undertaken in the United States. ${ }^{7}$ The empirical research from the United States has produced similar results to studies emanating from the United Kingdom, ${ }^{8}$ which is arguably more influential in Australia in terms of research methodology and access to justice policy. In the United Kingdom, independent socio-legal research focused on the wider community's experiences, expectations

$5 \quad$ Christine Parker, Just Lawyers: Regulation and Access to Justice (Oxford University Press, 1999). This work is heavily referenced in the Access to Justice Taskforce, above n 2.

6 MacDonald's fifth wave also relies on a detailed analysis of social, economic and political disenfranchisement by empirical methods. See MacDonald, above n 1 .

7 See Barbara Curran, American Bar Foundation, The Legal Needs of the Public: The Final Report of a National Survey (1977) and American Bar Association, Legal Needs and Civil Justice: A Survey of Americans (1994).

8 The findings of the American Bar Association survey have been summarised in Hazel Genn, The Hamlyn Lectures 2008: Judging Civil Justice (Cambridge University, 2010) 6-7. The results of the American Bar Association survey mirrored findings in Hazel Genn and National Centre for Social Research, Paths to Justice: What People Do and Think about Going to Law (Hart Publishing, 1999) discussed below in that two-thirds of respondents with justiciable problems did not enter the justice system. Limitations of these studies were recently considered by Marc Galanter, 'Access to Justice in a World of Expanding Social Capability' (2010) 37 Fordham Urban Law Journal 115; Also see MacDonald, above n 1, 13, 498-501. 
and behaviours when faced with legal problems and sought to reveal a comprehensive public perspective on issues of access to justice.

Dame Hazel Genn's 1999 book, Paths to Justice, ${ }^{9}$ became synonymous with this new multi-disciplinary approach to access to justice. ${ }^{10}$ Paths to Justice reported on the most wide-ranging survey of legal needs conducted in the United Kingdom to date. ${ }^{11}$ One of the most important insights of the Paths to Justice survey was its confirmation that there is no 'rush to the law' in the United Kingdom. ${ }^{12}$ While around 40 per cent of the general population had experienced a justiciable problem ${ }^{13}$ in the previous five years, only a tiny minority of those people found their way into any legal service or court. In response to the question of 'What do people want', Genn found:

When faced with a justiciable event most people simply want to solve the problem or to obtain compensation for harm and loss. The impulse for punishment, revenge, apologies or altruistic solutions is far less important than the desire to be rid of the problem ... members of the public want routes that are quick, cheap and relatively stress-free. That is true for all social groups. People want to get on with their lives as quickly as possible $\ldots^{14}$

The other key findings of the Paths to Justice research show that that justiciable problems commonly occur across all sectors of society and often in clusters. The most common problems involve faulty goods and services, money, injuries and work-related health issues, neighbours, employment, and divorce and separation. The most common strategy people employ is to try to sort out a problem by direct personal action and only a tiny minority of people when faced with a legal problem do nothing at all. If they do 'lump it' this is usually a deliberate choice, not due to apathy. The strategies people use for dealing with justiciable problems are influenced by a complex range of factors, including the nature of the problem and the knowledge and competence of the individual. ${ }^{15}$

The Paths to Justice legal needs survey was repeated periodically in the UK in the subsequent decade and disseminated for analysis by other organisations. The National Centre for Social Research (NCSR) in London undertook subsequent periodic large-scale legal needs surveys,

$9 \quad$ Hazel Genn and National Centre for Social Research (NCSR), above n 8.

10 See MacDonald, above n 1, 13, 500.

11 The research was conceived to address the concern that the Woolf reforms (Lord Woolf, Final Report to the Lord Chancellor on the civil justice system in England and Wales (1996)) were based on weak if not entirely absent evidence about the reality of access to justice from the perspective of citizens; See Genn, above n 8, 71.

12 Genn and NCSR, above n 8, 26.

13 Genn defined a judiciable problem as a problem which raises civil legal issues, whether or not this is recognised by those facing them and whether or not any action taken to deal with them involves the legal system. This definition has been preserved throughout the Australian A2JLN research discussed below.

14 Genn and NCSR, above n 8, 26.

15 Genn and NCSR, above n 8. 
reported in 2001, 2004, 2009 and 2012. The data in all these surveys have also been reanalysed to extract different information or address different questions (secondary analysis) for further published Reports in the United Kingdom. ${ }^{16}$ For example, the Legal Services Research Centre (LSRC) reported on a secondary analysis of the 2004 Civil and Social Justice Survey (CSJS) data which was designed to assess whether five groups of vulnerable or socially excluded people, including the elderly, differ in their problem resolution strategies and advice-seeking behaviour. ${ }^{17} \mathrm{Of}$ most relevance, in 2007, the peak not for profit ageing organisation in the United Kingdom, Age Concern, ${ }^{18}$ commissioned the LSRC to undertake even further analysis of the same data ${ }^{19}$ to explore in more detail the legal needs of older people. This Report provides a more focused picture of how the United Kingdom legal needs results apply specifically to older people ('the Age UK study'). ${ }^{20}$

The Age UK Study found that just over a quarter of older people surveyed report having encountered one or more civil law problems, which is a high prevalence of justiciable events comparatively to other groups in the larger survey. The most common causes of legal problems reported were consumer issues, neighbours, money or debt, personal injury, owned housing and clinical negligence, which was a different pattern to other groups. Long-term illness or disability, being in receipt of welfare benefits or having a very low income were shown to be particularly associated with prevalence of legal problems. Importantly, a quarter of the older people reported suffering stress-related ill-health and a fifth reported physical ill health as a result of their justiciable problem. Isolated older people were almost twice as likely to spend all of their time worrying about the problem compared to non-isolated older people. The reporting of legal problems appeared to fall with age, dropping from 35 per cent of people aged between 50 and 54 to 14 per cent of people aged 80 or over. ${ }^{21}$ Despite this, interestingly the older people represented in the Age UK Study most commonly turned to solicitors for advice and were less likely to approach non-legal advice services than younger people. In addition, approximately

$16 \quad$ See Kirby Swales, Measuring Legal Needs: Technical Report (National Centre for Legal Services Research, 2001). For an overview of the secondary analysis Reports arising from this Survey, see Pascoe Pleasence, Nigel J Balmer and Rebecca L Sandefur, Paths to Justice: A Past, Present and Future Roadmap (UCL Centre for Empirical Studies, 2013) 128-137.

17 Alexy Buck, Nigel Balmer and Pascoe Pleasance 'Social Exclusion and Civil Law; The Experience of civil Justice Problems Among Vulnerable Groups' (2005) 39(3) Social Policy and Administration 302.

18 Age Concern was the banner title used by a number of charitable organisations (NGOs) specifically concerned with the needs and interests of all older people (defined as those over the age of 50) based chiefly in the four countries of the United Kingdom. The successor charity, now the largest in Peak Body in the UK, is AgeUK < http://www.ageuk.org.uk>.

19 That is, the LSRC's 2004 CSJS data. In this study 'older people' were defined as over 50 years.

20 Age Concern, Civil and Social Justice Needs in Later Life (Age Concern, 2007).

21 Ibid, 1-2. 
half (52 per cent of older people felt that the advice they received from their first point of contact helped to bring about a better result which was higher than other groups. ${ }^{22}$

Demographic, institutional and cultural differences mean it is not possible to assume overall consistency between the United Kingdom results and the Australian access to justice landscape. It is possible however that older people in Australia may hold similar positive attitudes about the usefulness of the law in solving their disputes, and like their United Kingdom counterparts may be more inclined to access legal rather than non-legal services when faced with legal problems.

\section{Australian Legal Needs Research}

Unfortunately, unlike the United Kingdom, there has been a persistent absence of comprehensive and reliable data to gauge the Australian community's unmet legal needs. Access to justice research in Australia has however always benefited greatly from the perspectives of the community legal sector and the data produced relating to their work within the community. ${ }^{23}$ The area of access to justice for older people is no exception. Analysis of the information gathered by community legal centres provides important insights into the legal needs of older people in Australia. In relation to older people, the community legal sector has been at the forefront of developing integrated legal service responses for the elderly in direct response to their clients' legal needs. ${ }^{24}$ They have also contributed significantly to legal research through data collection and reporting on their complex casework. In addition to the daily work done by most generalist centres, Queensland, Victoria, New South Wales and Western Australia all have specialist seniors' legal services which use a multi-disciplinary approach to combining casework with outreach services, advocacy through in-house social workers and delivery of specialist community legal education programs. ${ }^{25}$ These specialist centres have also developed mutually beneficial partnerships with private elder law practitioners ${ }^{26}$ key government agencies such as public advocates, trustees and tribunals, and the peak ageing organisations. Many also partner directly with a non-government seniors organisation who provide helplines, manage phone enquiries and facilitate both legal, financial and other referrals. ${ }^{27}$

22 Ibid, 2. On the other hand, 7 per cent thought their first adviser made things worse.

23 See Jeff Giddings and Mary Anne Noone, 'Australian Community Legal Centres Move Into the Twenty First Century' (2004) 11(3) International Journal of the Legal Profession 257.

24 See Mary Anne Noone, 'Towards an Integrated Service Response to the Link Between Legal and Health Issues' (2009) 15 Australian Journal of Primary Health 203.

25 See for example; Seniors Rights Victoria <http://seniorsrights.org.au/>.

26 For example, Seniors Rights Victoria operates four pro bono staffed outreach legal clinics in health centres in partnership with private firms in Melbourne. Further information, above n 25 .

27 For example, Seniors Rights Victoria helpline operated by Seniors Information Service at COTA (Vic). For further information see, above n 25. 
Although these integrated community services produce quality data concerning the access to justice issues faced by older people, they are not funded to examine, analyse or investigate this data and do not have the resources to do so. The legal needs research that has been undertaken, while individually usually of high quality, has remained constricted due to resources and methodology. ${ }^{28}$ Speaking in August 2010, Justice Ronald Sackville AO lamented the contemporary access to justice 'jigsaw' in Australia:

Australia has had too many ad hoc, repetitive and ineffectual inquiries into access to justice. There have been too few rigorous empirical studies evaluating programs and charting their progress over time. Too few studies have attempted to cross boundaries and derive lessons from studies or experiments on service delivery have been conducted largely in isolation from each other. ${ }^{29}$

The most comprehensive and robust program of legal needs research in the past decade has been produced by the New South Wales Law and Justice Foundation and more specifically the Foundation's Access to Justice and Legal Needs Research Program (A2JLN). The A2JLN Program seeks to provide a thorough and sustained assessment of the legal needs of the community in New South Wales, with a focus on access to justice by disadvantaged people. A further commitment of the A2JLN has been to ensure the information obtained by their research is easily accessible by the community and widely disseminated to promote further analysis. ${ }^{30}$ Prompted by concerns about the impact of the ageing population and lack of data about access to justice and the elderly, the first volume of the A2J Reports published in 2004 was a qualitative study of the legal needs of older people (Older People Report). ${ }^{31}$

In 2006 the A2JLN Program reported on its first broad-scale quantitative study on legal needs; the NSW Legal Needs Survey (NSW Survey) provided valuable empirical data on legal service provision and law reform

28 See Susannah Sage Jacobson 'The Ongoing Search for a Demand-Side Analysis to Access to Justice in Australia' cited in Australasian Institute of Judicial Administration, Australian Courts: Serving Democracy and its Publics 2013 (2013) 49. For an international perspective, see Catherine R Albiston and Rebecca L Sandfur 'Expanding the Empirical Study of Access to Justice' (2013) Wisconsin Law Review 101.

29 Ronald Sackville 'Access to Justice: Towards an Integrated Approach' (2011) 10 The Judicial Review 221, 235-256.

30 See the many publications and reports available on the website of the Law and Justice Foundation of New South Wales, Access to Justice and Legal Needs Program <http://www.lawfoundation.net.au/>. The A2JLN has most recently led research on community participation on law reform, the legal needs of particular socially disadvantaged groups such as the homeless, prisoners, the mentally ill, the disabled and older people, and considered issues such as non-legal and legal service provision to people with complex needs in remote areas of Australia.

31 See Geoff Mulherin, 'Foreword' in Sarah Ellison et al, The Legal Needs of Older People in NSW, Access to Justice and Legal Needs Volume 1 (2004) 398. In particular, there were three Interim Reports published before the Older People Report, a Report on the Public Consultations, a quantitative pilot legal needs survey from Bega valley and a Data Digest. 
in New South Wales. ${ }^{32}$ Drawing on the methodology from Paths to Justice, the NSW Survey reported similar results to the United Kingdom study. Like Paths to Justice, the NSW Survey confirmed there is overall no rush to the law by the people in these geographical areas in New South Wales. In fact, the NSW Survey found that one-third of these particular communities who face justiciable issues do nothing about it at all. ${ }^{33}$

The NSW Survey reported a relatively high incidence of legal events over a one-year period, with some individuals, such as those with a chronic illness or disability, experiencing 'clustering' of legal events. ${ }^{34}$ The type of legal event and socio-demographic factors were a significant predictor of whether or not people acted in response and whether they then sought help from others. The Survey also confirmed that people rarely sought advice from legal advisers, but that in three-quarters of the cases where help was sought, only non-legal advisers were consulted..$^{35}$ The most common accompanying belief to inaction was that doing something about the legal issue would make no difference to the outcome. ${ }^{36}$ Overall however, satisfaction with the assistance received for an event was related to the type of legal event rather than the adviser, and generally there was a high rate of satisfaction with the outcome of events among those people whose legal event had resolved. Participants were more likely to be satisfied with the outcome of events where they sought help than where they did nothing.

The key results from the NSW Survey were largely confirmed by similar results and findings emerging in the subsequent A2JLN AustraliaWide survey, published in 2012. ${ }^{37}$ The Legal Australia-Wide Survey (LAW Survey) was an ambitious and long-awaited quantitative study of legal needs across and throughout the whole of Australia. The aim of the $L A W$ Survey was to:

[D]eal with key questions that go to the heart of understanding the legal and access to justice needs of the community and how to address these needs. It assesses the prevalence of legal problems across the community and the vulnerability of different demographic groups to different types of legal problems. It examines the various adverse consequences that can

32 See Christine Coumarelos, Zhigang Wei and Albert Zhou, Justice Made to Measure: New South Wales Legal Needs Survey in Disadvantaged Areas (2006) 350. This study focused on legal needs in six disadvantaged areas in NSW was administered during September and October 2003 via telephone interviews of a total of 2431 residents.

33 Ibid, 100.

34 Ibid, 100. Clustering Socio-demographic factors other than age were also reflected in incidence of legal events.

35 Ibid, 215. Type of non-legal assistance were reported to include friends, family, non-legal professionals and other non-legal forms of help, such as medical assistance or financial advice.

36 In addition to older people, the youngest respondents, Indigenous Australians, and people with low levels of education, were also most likely not to respond to a legal issue. Coumarelos et al, above n 32, 100.

37 Christine Coumarelos et al, Legal Australia-Wide Survey, Access to Justice and Legal Needs Volume 7 (2012) 361. 
accompany legal problems as well as the responses people take when faced with legal problems and the outcomes they achieve. ${ }^{38}$

Like the NSW Survey, the LAW Survey collected data on the entire population of the geographical areas surveyed rather than focusing on older people. It therefore remains difficult to distil a coherent picture of older people's legal needs from the results. While these reports taken together do not provide a full picture of the legal needs of older people in Australia, it is possible to identify some of the key pieces of their distinctive access to justice puzzle. ${ }^{39}$

\section{Prevalence of Legal Need and Barriers to Access to Justice}

The age and 'life-stage' of groups of people in the Australian community affect the access to justice issues they experience. This has been shown in relation to four different issues; the prevalence or incidence of legal needs, in relation to seeking advice and accessing the legal system, the rates of resolution of the legal problem, and the quality of outcome.

First, the current available evidence does not indicate that older people currently have a higher incidence of legal need than the general population statistically. In fact the results indicate they have the lowest. ${ }^{40}$ This is arguably because consumer and financial problems give rise to the most frequent legal needs reported in Australia and older people are likely to be engaged in proportionately fewer consumer transactions than younger demographic cohorts. The data concerning overall incidence of legal needs is linked to population statistics, therefore as the proportion of older people in the community rises over time the incidence of legal needs of older people will also increase steadily.

It is also important to note that the research confirms that older people do experience a distinctive pattern or cluster of legal issues that are lifecycle and lifestyle related. These reflect the complex legal needs of ageing, such as significant health and accommodation changes.

Secondly, older people across Australia are disproportionately less likely to seek resolution of their 'justiciable event' by seeking advice or accessing the legal system. ${ }^{41}$ People aged 65 or over ranked second on a table of demographic groups with 'significantly lower odds of taking action in response to a legal problem compared to their counterparts'. ${ }^{42}$ The people least likely to seek or take advice were those whose main language was not English. This suggests that older people whose first or main language is not English are a particularly vulnerable demographic for legal needs and access to justice purposes. It is also important to note

$38 \quad$ Ibid, 231.

39 The overall findings of both reports as they relate to legal assistance services have been analysed in Pascoe Pleasence et al, Reshaping Legal Assistance Services, Building on the Evidence Base: A Discussion Paper (2014) 194.

40 Coumarelos et al, above n 37, 16.

41 Ellison et al, above $\mathrm{n} 31, \mathrm{xv}$.

42 Coumaleros et al, above n 37, 230. 
that it is not possible to make generalised assumptions across all groups of cultural and linguistically diverse older people about their attitudes to the Australian legal system or their levels of psychological resilience.

Thirdly, in relation to resolution of legal issues, age and disability status were found to be the only socio-demographic characteristics that were significant factors in the outcomes of legal events. ${ }^{43}$ Older people and those with a disability had the lowest resolution rates. These findings correlated with older people not acting or seeking help in response to legal issues. ${ }^{44}$

Finally, of perhaps greatest concern, older people were enduring lessfavourable outcomes to their legal problems than the wider community. The Age UK Study found similar patterns: seeking advice, taking action and satisfaction with outcomes all declined with age. ${ }^{45}$

While older people experience fewer justiciable events than other members of the Australian population, they suffer the most significant barriers to access to justice. They experience limitations in seeking advice, tolerate the lowest levels of resolution and obtain the least optimal outcomes to legal issues, indicating that they are the most likely to benefit from the greater levels of assistance to resolve their legal problems.

\section{E The Relevance of Personal Attributes of Older People}

The evidence from the legal needs research is far less useful in shedding light on the particular reasons why older people do not access advice or services in response to their legal problems, or the specific barriers they face in accessing the law. The aim of the Older People Report was:

[T]o identify the particular legal issues which often confront older people in NSW. It looked at the particular barriers confronted by older people in accessing services to resolve legal issues, including any attitudinal barriers. ${ }^{46}$

In response to the question of whether there are any 'attitudinal' attributes that older people hold which may affect their access to justice, the Older People Report found:

Older people are not a homogeneous group ... they comprise diverse cultural and linguistic backgrounds, level of education, family arrangements, socioeconomic status. Nevertheless, some common themes were evident from our consultations and submissions received ... ${ }^{47}$

Many of the obstacles for older people in accessing legal services reflect characteristics of the current cohort of older people, including a lack of

43 Coumelaros et al, above n 32, 100.

44 Ibid, 96.

45 There are, however, some limitations to comparing this data as the sample analysed were over 50s rather than the group identified in the A2JLN studies of over 65. The Age UK Report was unequivocal in its findings however that the least likely group to seek assistance were the eldest; up to 30 per cent in the over 80s. Age Concern, above n 20, 1-2.

46 Emphasis added. Ellison et al, above n 31, xv.

47 Ibid, 29. 
awareness of their legal rights, a lack of confidence in enforcing those rights, a reluctance to take legal action and a perception that the law is disempowering and cannot solve their problems. ${ }^{48}$

Data from both the NSW Survey and LAW Survey did not support a finding that older people were any less aware, lacking in confidence or more reluctant to seek legal assistance than people of all other ages in the community at large, particularly given the high degree of complexity of the areas of law involved in elder law matters.

The LAW Survey Report also speculated that the personal attributes of resilience, or ignorance either about services available or the nature of their own problems, may also play a role in the lack of engagement with the law found amongst the elderly:

The reason for the lower reporting levels by older people is unclear. Older people may actually have a lower prevalence of legal problems because their life circumstances are less likely to expose them to legal problems or because they are better able, through experience to deal with the issues before they escalate. However the lower reporting by older people may also partly reflect a failure to identify legal needs, for reasons such as a decrease in the importance placed on problems or an increased ignorance of personal circumstances. ${ }^{49}$

On the available evidence, it would be equally plausible to assert that older people are not ignorant of their predicament and do want equal access to justice but are not able to overcome barriers caused by and located within the formal legal system. Although costs and delay deter all people with legal needs, the complexity and multiplicity of the specific legal areas most often faced by older people may be one causal factor. The emerging specialist practice area of Australian elder law has identified the distinctive impact on older clients caused by the particular areas of practice they face across all Australian States. These areas of law include: Accommodation, Health, Financial and Consumer, Discrimination, Elder Abuse, Substitute Decision-Making, and End-of-Life and Grandparenting. ${ }^{50}$

Another equally plausible explanation is that the attitudes of older people may involve a more holistic view of their legal needs and access to justice that extends beyond the formal legal system. Older people's perceived reluctance to seek out the law may be the exercise of a deliberate choice to seek out other types of informal dispute resolution that are more effective or responsive to their priorities.

Another difficulty with making assumptions about legal needs based on perceived attributes of any cohort of older people is the ongoing pace of change over time. In the intervening ten years since the Older People Report, with the first 'baby-boomers' hitting retirement age, the demographics of older people in 2015 has already changed markedly in

48 Ibid, xxxi.

49 Coumaleros et al, above n 37, 230.

50 Ellison et al, above $\mathrm{n} 31$. These areas of law are set out as key chapter headings and while now over 10 years old, the Older People Report made a significant contribution to the development of Australian Elder Law simply by identifying these discrete legal practice areas of most importance to older people. 
Australia, both in size and diversity. ${ }^{51}$ Significant demographic changes and growth in ageing populations suggests that a worthwhile aim of legal needs research must be the discovery of factors that may apply to distinct cohorts of older people rather than across the older population generally. ${ }^{52}$

\section{Access to Justice Policy in Australia}

Despite the weight of the legal needs research in Australia and internationally, Australian access to justice policy has not yet adequately recognised the distinctive nature of the access to justice challenges faced by older people. Only basic statistical findings relating to the prevalence of legal needs across the community has cut through to have any influence on the development of access to justice policy in Australia over the past decade. The significant clearly documented barriers to assistance have not been addressed nor have the causes been identified. The most recent comprehensive policy on access to justice released by the Federal Government in 2009 (A2J Strategic Framework) relied almost exclusively on the NSW Survey. ${ }^{53}$ The policy makers appear to take a simplistic view without recognising the underlying questions raised by legal needs research and the theoretical link back to the "whose access to which justice' question.

Developing coherent access to justice policy grounded in evidence-based legal needs requires leadership concerning which justice the government seeks to deliver. Embedded in the identification of which justice is then also the question of how much of that justice does the government believe is needed. To what extent is it acceptable that some barriers to access, particularly those in relation to cost, continue to exist? An approach that takes focus away from reducing the barriers then necessarily asks to what extent should we be focusing on supporting the community to manage their own disputes, or develop the personal attributes to manage them? Genn argues:

The central dilemma in the access to justice argument is whether the objective of legal policy should be to enhance access to legal forums for the resolution of disputes or whether it should be aimed at preventing problems and disputes from arising, equipping as many members of the public as possible to solve problems when they do arise without recourse to legal action ... It is not an answer to say they should be twin objectives of policy, because they logically conflict. ${ }^{54}$

$51 \quad$ For example, the findings about barriers caused by technology are not likely to be as marked in the current cohort of older people. See Ellison et al, above n 31, 41-43.

52 In the UK they have sought to do this through periodic repeated data collection.

53 Access to Justice Taskforce, above n 2. Some supporting references were also made to the Paths to Justice Research in the UK and also a Victorian study, cited at Ipsos Australia, Dispute Resolution in Victoria: Community Survey 2007 Report (2007).

54 Genn and NCSR, above n 8, 263. 
Indeed, A2J Strategic Framework devoted a considerable part of its strategy to developing the attribute of 'resilience' to legal disputes within the community. ${ }^{55}$ The policy posits:

One of the most cost effective ways of resolving disputes is where people resolve disputes themselves - or where a dispute can be prevented from occurring at all. ${ }^{56}$

The policy does not go on to explain how this resilience to self-manage or avoid disputes is cost effective or preferable to anyone beyond the government itself. Such an analysis would require evidence that this attribute of resilience leads to positive outcomes to legal problems that are satisfying to distinctive and diverse groups of people. Further, it does not explain how this attribute of resilience may be measured between types and groups of people and whether the groups who are found to be less resilient are going to be blamed or supported as a result.

The notion of building personal resilience as an aim of justice policy may also become significant in terms of policy to assist older people. The presence of this attribute in older people was considered as a possible reason for lower levels of justiciable events being reported in the legal needs data. ${ }^{57}$ While it is established that older people are generally likely to have higher levels of psychological resilience than the general community, the proposition that the psychological conception of resilience has any relationship with avoiding legal disputes has not yet been tested in any of the research surveyed for this article.

\section{A Dangers of the Costs-Focused Approach to Policy for Older People}

The A2J Strategic Framework expressly identified efficiency and expediency as the priority for the formal legal system as part of the which justice equation. This was at least partly in response to the increasing strain on the government's financial budget of delivering the existing model of courts and public legal services over the past two decades. Justice policy in Australia has become a key public battleground for limited financial resources with policy rhetoric about access to justice delivered together with an underlying context of pressure to decrease the cost of particular justice services such as legal aid. ${ }^{58} \mathrm{~A}$ focus on shrinking budgets and reducing legal and justice services as the context for access to justice policy becomes a particularly complicated tension where older people are concerned. The results of the legal needs data suggests that older people have the least prevalence of legal problems of all demographic groups in the community. This potentially justifies the least resource allocation

55 Access to Justice Taskforce, above n 2, 147-159. As above, the term 'resilience' is not defined in the policy documents but has been assumed to mean psychological resilience.

56 Ibid, 147.

57 Coumaleros et al, above n 37, 50 .

58 Genn, above n 8. 
across the community, even in the face of similarly powerful evidence that the particular barriers of access to justice are the most significant for older people.

As evidence of the central place of costs in the access to justice policy landscape, the Australian Productivity Commission was recently tasked to inquire into 'Australia's system of civil dispute resolution, with a focus on constraining costs and promoting access to justice and equality before the law'. ${ }^{59}$ There is an inherent contradiction between these two key aims of the inquiry, and, perhaps as a result, the recommendations mirror a simplistic view of the legal needs research. In response to the prevalence of legal needs in disadvantaged groups, the Productivity Commission recommended targeting of legal assistance to people in the community 'who are at risk of experiencing social exclusion'. ${ }^{60}$ The $L A W$ Survey established however that measures of social exclusion or social needs do not readily equate to addressing issues of barriers to access to justice. ${ }^{61}$ If such a model is employed by access to justice policy, older people as a demographic group in particular risk remaining unrecognised and not prioritised for adequate resources to address their particular barriers to justice. The Productivity Commission in fact reduced the consideration of the barriers to access to justice to a simple cost-benefit type analysis:

Given limited resources, it is important to understand what is being traded off - for example, if more resources are dedicated to improving access to justice, by how much are the barriers reduced? And does this make society as a whole better off? ${ }^{62}$

This analysis implies that specialist legal services providing targeted integrated services to the elderly should need or be able to justify their funding on a society-wide basis. This will not be achievable against current evidence that older people have the lowest incidence of legal events overall. ${ }^{63}$

59 Productivity Commission, Access to Justice Arrangements: Draft Report (2014) iv.

60 Ibid, 33-34. This recommendation was noted to be consistent with the most recent COAG Agreement on targeting legal services. A social exclusion measure would include some older people, however it does not recognise all older people as a demographic group; see Riyana Miranti and Peng Yu 'Persistence of Social Exclusion among Older People in Australia: What are the protecting factors?' (Paper presented at HILDA Survey Research Conference, National Centre for Social and Economic Modelling, University of Canberra, 2011).

61 This finding has also been supported internationally. See Albiston and Sandfur, above n 28,110 .

62 Productivity Commission, above n 59, 749-760. Note that the Productivity Commission did however make some useful recommendations to acknowledge and address the lack of reliable data available to analyse the complexity of questions such as this. The Draft Report recommended that a survey such as the LAW Survey be funded to be conducted every five years.

63 See Susie Forell and Abigail Gray, Outreach Legal Services to People with Complex Needs: What Works?, Justice Issues Paper 12 (2009) and Pleasence et al, above n 39, 17 . 
These complex difficulties in conceptualising the priorities of access to justice are by no means unique worldwide. Speaking from her experience in both the United Kingdom and the United States, Rebecca Sandfur has explained:

On what might be termed the "demand side" of access to justice, we have only a very rudimentary understanding of how people come to think about and act on their potentially justiciable experiences and of the consequences of these experiences for them and for society. For example, we know very little about the forces that shape public demand for legal services. Here, the pull of the policy audience has resulted in a limited and restricting understanding of "legal need." Well-meaning observers often speak and write as though access to justice is only an issue for the poor, and assume that poor people desire lawyers' services but cannot obtain them because those services are so very expensive. In fact, the picture is much more complex: civil justice problems are ubiquitous, both poor and non-poor people typically do not think of their civil justice problems in legal terms, people often do not think of lawyers' services as a helpful route to solving civil justice problems, private lawyers' services are not always that expensive, and concerns about cost play only a small role in people's decisions not to turn to lawyers or to courts. ${ }^{64}$

A similarly complex picture emerges concerning older people as users of legal institutions and processes such as alternative dispute resolution (ADR). While mediation has emerged as a favoured justice policy measure in Australia in the past decade, this has been largely due to a perception that it is cheaper than court and tribunal hearings, rather than empirical evidence that it necessarily produces better outcomes, particularly for disadvantaged or vulnerable people. ${ }^{65}$ While mediation may provide benefits to older people in avoiding the problems associated with adversarial adjudicative processes, an access to justice policy that promotes ADR without analysis of the possible inherent imbalances of power may simply serve to further disempower older people and diminish their equality before the law. ${ }^{66}$ The development and outcomes of mediation for the resolution of disputes involving older people has not yet been a focus of empirical legal research in Australia.

\section{B The Rise of Rights-Based Ageing Policy}

While justice policy appears to be oversimplifying and failing to prioritise access to justice for older people, the ageing policy in many States and Territories in Australia now recognises and promotes equality before

64 Albiston and Sandfur, above n 28, 117. This passage also usefully cites some of Sandfur's previous work.

65 See Joan Braun, 'Elder Mediation: Promising Approaches and Potential Pitfalls' (2013) 7 Elder Law Review 1. Note that detailed discussion of the use of mediation in courts and tribunals and with vulnerable people is beyond the scope of this article.

66 For an overview of the emerging specialist ADR practice of Elder Mediation, see Lise Barry, 'Elder Mediation: What's in a name?' (2015) 32(3) Conflict Resolution Quarterly 1. 
the law. ${ }^{67}$ These multi-agency or whole-of-government policy priorities appear to have evolved from concerns about the prevalence of and prevention strategies for elder abuse in light of the rise of human rights based discourse within the ageing sectors in Australia and internationally. ${ }^{68}$ Almost all Australian States and Territories ${ }^{69}$ have some policy framework for addressing elder abuse in which the 'centrality of human rights is embedded in principles underpinning the document'. ${ }^{70}$ In Wendy Lacey's recent analysis of Australia's international human rights obligations to older people, she resolved:

That Australia's legal and policy frameworks for dealing with elder abuse are so weak is a national disgrace and it is time that lawyers joined the calls for a better system of adult protection in Australia. However, any system must be framed from a rights perspective to ensure that ageist and paternalistic approaches are not adopted, thereby avoiding the erosion of the rights and freedoms of vulnerable adults under the guise of safeguarding or protecting those people. We should adopt a progressive approach to the interpretation and implementation of existing international human rights norms. ${ }^{71}$

These human rights norms are grounded in the central tenet of equality before the law, so that these policy directions lead back to questions about why the Australian legal system does not currently prioritise addressing the barriers to access to justice for older people. Indeed, the recent elder law reform attention by the Australian Law Reform Commission in the Statebased jurisdiction of guardianship laws and legal capacity in Australia coincided directly with negative attention from an international human rights committee concerning the inadequacy of these particular current Australian laws. ${ }^{72}$ The pressure for law reform in the area of substitute decision-making and capacity has arguably been led by disability and mental health advocates and grounded in the International Convention

67 These policies are usually located in health, social inclusion, family or communities portfolios, depending on the priorities of the State Government involved.

68 See Wendy Lacey, 'Neglectful to the Point of Cruelty: Elder Abuse and the Rights of Older Persons in Australia' (2014) 36 Sydney Law Review 99, 127. There is no independent empirical research on the incidence of elder abuse in Australia.

69 Ibid. With the exception of Queensland and the Northern Territory, Queensland has a dedicated seniors' legal service and an information and referral service with an emphasis on data collection. Western Australia does not have a government policy, but the Alliance for the Prevention of Elder Abuse ('APEA') has developed a resource: Elder Abuse Protocol: Guidelines for Action.

70 Ibid.

71 Ibid, 130. See the conclusions of the Office of the High Commission for Human Rights ('OHCHR'): OHCHR, Normative Standards in International Human Rights Law in Relation to Older Persons: Analytical Outcome Paper (August 2012) <http://social.un.org/ageing-working-group/documents/ohchr-outcomepaper-olderpersons12.pdf> ('OHCHR Report').

72 See Australian Law Reform Commission, Equality, Capacity and Disability in Commonwealth Laws Final Report, ALRC Report 124 (2014). It is noted that only Victoria and the Australian Capital Territory have legislation requiring parliamentary scrutiny of Human Rights: Human Rights Act 2004 (ACT); Charter of Rights and Responsibilities Act 2006 (Vic). 
on the Rights of Persons with a Disability rather than an acknowledgement of the particular plight of older people. However, the likelihood of a similar international human rights convention being introduced by the United Nations in the next decade addressing the particular concerns of older people also appears to have strength. ${ }^{73}$ This may be expected to add an increased impetus for Australian policy makers to attend to the legal needs of the ageing population. ${ }^{74}$

Another source of the expansion of human rights principles evident in the ageing sector was the Federal Government's 2012 aged care reform agenda. ${ }^{75}$ Following these reforms, all residents and recipients of aged care services have the benefit of 'Charters of Rights' attached to the Aged Care Act 1997 (Cth), in addition to access to the Aged Care Complaints Scheme under the oversight of an independent Aged Care Commissioner. Arguably the recipients of Commonwealth services should not be afforded better access to justice in this area than other older people. In relation to discrimination law, the Australian Human Rights Commission recently found alarming rates of ageism and that negative attitudes towards older people remains a pervasive problem throughout Australian society, with significant effects on the quality of life of older people. ${ }^{76}$ This evidence about the predominance of ageism confirms that any rights based approach to addressing legal needs and access to justice should avoid making assumptions about older people's personal attributes or attitudes about the law and focus on gathering real evidence on how to empower them or facilitate their access to justice in ways that are meaningful to them.

\section{Conclusion}

Legal needs research in Australia and internationally has provided some evidence about how and why people use the justice system and where barriers to equality before the law exist. The legal needs of differing groups of people are complex and change over time. While socio-economic

$73 \quad$ A new International Convention on the Rights of Older Persons, currently being considered at the United Nations by the Open-Ended Working Group on Ageing - established by General Assembly Resolution in 2011: Follow-up to the Second World Assembly on Ageing, GA Res 65/182 UN GAOR, 65th sess, 71st plen mtg, Agenda Item 27(c), UN Doc A/Res/65/182 (4 February 2011) [28]. See Lacey, above n 68, and Israel Doron and Benny Spanier, 'International Convention on Rights of Older Persons: Where We Were, Where We Are and Where Are We Going?' (2012) 8 Global Ageing 7.

74 For an example of a rights-based aged sector perspective, see Council on the Ageing, Rights Respect, Recognition: A New Deal For Older Australians (2013).

75 See Lacey, above n 68, 123-126. See also Productivity Commission's inquiry into aged care services in Australia; Productivity Commission, Caring for Older Australians, Inquiry Report No 53 (2011) and the position paper outlining the human rights approach for the implementation of the aged care reforms; Australian Human Rights Commission, Human Rights Approach to Ageing and Health Respect and Choice (2012).

76 Australian Human Rights Commission, Fact or Fiction? Stereotypes of Older Australians, Research Report (2013). 
measures provide some understanding of disadvantage and inequality before the law, legal needs are not neatly aligned with social needs. Lifecycle factors create specific areas of elder law and complex legal challenges for ageing Australians. Therefore, a focus on ageing as a priority for access to justice policy measures is appropriate.

Older people do suffer a distinct disadvantage in access to justice. While not currently proven in terms of the prevalence or incidence of legal problems, the evidence does show that older people face particularly strong barriers to gaining legal assistance and achieving satisfactory resolution compared to other Australians. Unfortunately however, the exact causes of the impediments faced by elderly in accessing the law have not yet been identified by evidence-based research.

The known psychological resilience of older people, or a preference for more holistic conception of justice than is offered by formal legal services, may affect older people in seeking out the law. In light of the current lack of research, it is crucial that access to justice policy does not rely solely on assumptions about personal attributes or attitudes of older people in relation to the law or fall back on an untested notion that psychological resilience reduces legal need.

There needs to be further targeted empirical research to identify the substantive reasons why older people do not currently enjoy equality before the law. We need to know whether older people are locked out by the legal system itself that fails to recognise their needs or whether their absence is the exercise of a conscious choice some combination of these and other factors. 